\title{
Lamentación sobre Cristo muerto de la catedral de Santa María de Vitoria-Gasteiz atribuido a Gaspar de Crayer. Revisión y nuevas aportaciones
}

\author{
FERnANdo R. BARTOLOMÉ García ${ }^{1}$
}
The Lamentation over the dead Christ, atributed to Gaspar de Crayer, in Vitoria-Gasteiz s cathedral. Revision and new contributions

\begin{abstract}
RESUMEN
El lienzo de la Lamentación sobre Cristo muerto atribuido a Gaspar de Crayer sigue siendo una de las obras más destacadas de la catedral de Santa María de VitoriaGasteiz. Es parte del ajuar mueble de las capillas de San Prudencio y Santo Cristo de las que fueron patronos los hermanos

Galarreta, Secretarios de Estado y de
\end{abstract} Guerra en Flandes.

PALABRAS CLAVE: Lamentación, Gaspar de Crayer, Galarreta, catedral, Vitoria.

\begin{abstract}
The Lamentation over the dead Christ $s$ canvas, atributed to Gaspar de Crayer, is one of the most important art works in the catedral of Vitoria-Gasteiz. This painting was situated in Saint Prudence and Saint Christ chapels, which were founded by Galarreta brothers, who had responsible jobs in the north of Europe.
\end{abstract}

KEY WORDS:

Lamentation, Gaspar de Crayer, Galarreta, cathedral, Vitoria.

Con motivo de la restauración del lienzo de la Lamentación sobre Cristo muerto, hoy en el Museo Diocesano de Arte Sacro, aunque originario de las capillas de San Prudencio y Santo Cristo de la catedral de Santa María de Vitoria, a las que perteneció, decidimos aventurarnos en un estudio histórico-artístico que englobara la fundación y patronato de estas capillas y todo su complemento mueble ${ }^{2}$ (Fig. 1). La importancia de este lienzo y la falta de un estudio monográfico del mismo nos animaron a llevar a cabo este trabajo. Nuestra intención no ha sido otra que reordenar todo lo que se ha dicho hasta el momento mediante un exhaustivo

1 EHU-UPV / UNED Bizkaia. E-mail: fbartolome@portugalete.uned.es

2 BARTOLOMÉ GARCÍA, F. R., «Fundación y patronato de los Alday y Galarreta. Las capillas de San Prudencio y Santo Cristo en la catedral de Santa María de Vitoria-Gasteiz», Ars Bilduma. Revista del Dpto. de Historia del Arte y Música de la U.P.V., no 0 (2010), pp. 14-39. 
estado de la cuestión y aportar nuevas hipótesis y datos que ayuden a replantearnos algunos aspectos que hasta el momento se daban por válidos sin una pertinente comprobación. Es cierto, como se ha mantenido a lo largo del tiempo, que la obra debe vincularse al patronato fundado por los hermanos Galarreta (Francisco y Martín) en la capilla del Cristo de la antigua colegiata de Vitoria. Hasta ahora se ha señalado en la mayor parte de los trabajos a Francisco de Galarreta como el artífice del encargo y posterior envío a la capilla de este lienzo. Nunca sabremos con certeza quién de los dos hermanos la compró, pero sí que hemos podido demostrar que fue Martín de Galarreta el encargado de enviarla y colocarla en la capilla que había construido como lugar de enterramiento para su familia entre 1661 y 1663, varios años después de la muerte de su hermano Francisco. Es evidente que el tema de la Lamentación era el adecuado para una capilla funeraria dedicada al Santo Cristo y levantada para honrar la memoria de los hermanos Galarreta.

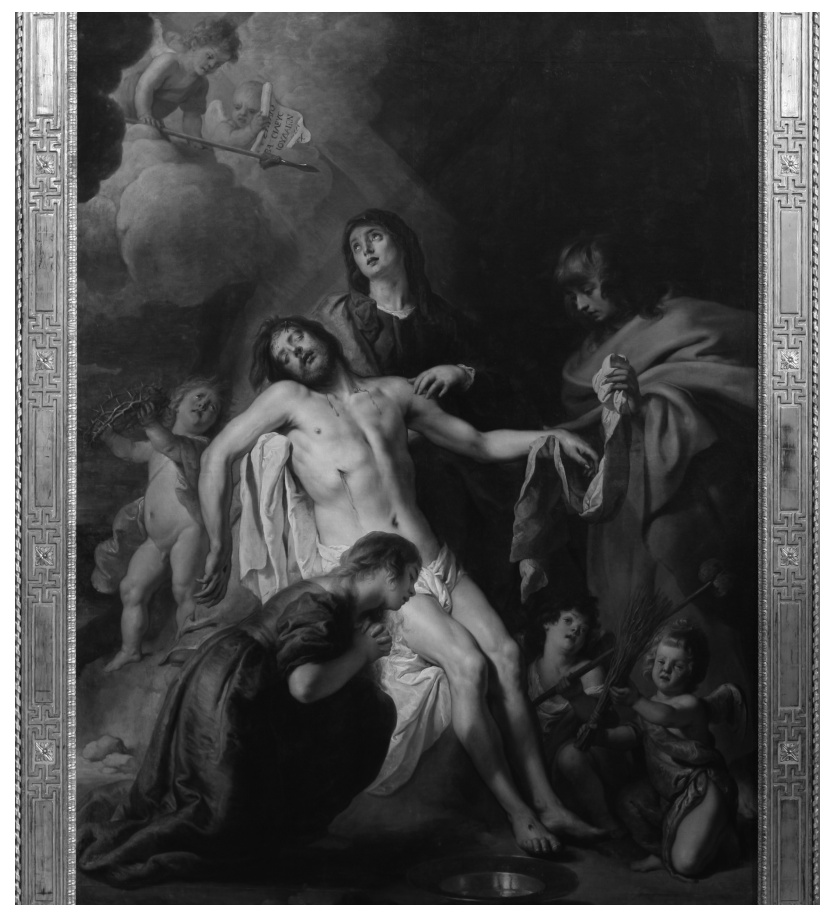

Fig. 1. Gaspar de Crayer (atrib.) Lamentación sobre Cristo muerto. Vitoria-Gasteiz. Museo Diocesano de Arte Sacro. Elizbarrutiko Arte Sakratuaren Museoa.

Este magnífico lienzo permaneció en el olvido desde su llegada a Vitoria hasta el siglo XVIII. En concreto fue en 1785 cuando importantes artistas madrileños redescubrieron esta pintura de la oscuridad en la que se hallaba en la capilla de San Prudencio de la colegiata vitoriana. A partir de este momento, y tras su reubicación en la sacristía, fueron muchos los viajeros, ilustrados y estudiosos quienes se fijaron y dedicaron algunas palabras de elogio a esta pintura. El primero fue 
Lamentación sobre Cristo muerto de la catedral de Santa María de Vitoria-Gasteiz...

Gaspar Melchor de Jovellanos, en su diario escrito en 1791; consideraba que este bellísimo cuadro parecía de Rubens, aunque «dicen ser de Van Dyck» y que según la tradición procedía de Sevilla ${ }^{3}$. Un año más tarde en la Guía de Forasteros atribuida a Lorenzo de Prestamero, se considera obra posible de Murillo imitando el estilo de Van Dyck y dádiva de Francisco de Galarreta, descartando que fuera enviado por Pedro López de Alday, pues no coincidió en el tiempo con la época de Murillo4. Viajeros ingleses del siglo XIX como Martín Haverty (1844) o Terence M. Hughes (1847) coinciden en sus guías de viajes por España que en la colegiata de Santa María se «encierran algunos cuadros valiosos de Van Dyck, Ribera, etc.»5 . En 1884 Ricardo Becerro de Bengoa se refiere someramente a este cuadro señalando que está atribuido a Van Dyck ${ }^{6}$. Un año más tarde se publicaba el tomo dedicado a las Provincias Vascongadas de la colección España sus monumentos y artes, su naturaleza e historia de Antonio Pirala. En esta obra de nuevo se refiere a la sublime Inmaculada de Carreño y al cuadro de la Piedad atribuido a Van Dyck ${ }^{7}$. El gran cronista de la ciudad de Vitoria don José Cola y Goiti habla de este cuadro en varias ocasiones, tomando como fuente lo referido en la Guía de Forasteros publicada por la Real Sociedad Bascongada de los Amigos del País en 1792. Insiste en sus distintas publicaciones que es obra de Van Dyck o tal vez de Murillo imitando su estilo ${ }^{8}$.

La atribución a Van Dyck la consolidó a partir de 1906 el insigne historiador del arte Elías Tormo en un apasionado artículo publicado en Cultura Española. En él considera que «se trata del mejor Van Dyck de asunto religioso que hay en España». Años más tarde, en 1917, reeditó parte del mismo artículo en la revista Ateneo en el que mantiene intacto todo su entusiasmo y admiración hacia esta obra ${ }^{9}$. Carreras y Candi en su Geografía del País Vasco y siguiendo seguramente los estudios de Tormo, afirma con rotundidad que la Piedad que representa a Jesús bajando de la cruz es de Van Dyck ${ }^{10}$. En el Catálogo Monumental de España en su

${ }^{3}$ SANTOYO, J. C., Viajeros por Álava (siglos XV a XVIII), Vitoria, 1972, pp. 180-181.

4 Guía de forasteros en Vitoria por lo respectivo a las tres Bellas artes de pintura, escultura y arquitectura, con otras noticias curiosas que nacen de ellas, Vitoria, 1792, p. 19. TABAR, F., «La guía de forasteros en Vitoria por Lorenzo Prestamero", en Lorenzo Prestamero (1733-1817) una figura de la ilustración alavesa, Vitoria, 2003, pp. 118-119.

5 SANTOYO, J. C., SILLAURREN, R. M., SANTAMARÍA, J. M., Viajeros ingleses del siglo XIX, Vitoria, 1978, pp. 216, 223.

6 BECERRO DE BENGOA, R., El libro de Álava, (1877), ed. Roger, Donostia-San Sebastian, 2000, p. 117. BECERRO DE BENGOA, R., «Álaba en la Euskal-Erria. La catedral de Vitoria» Euskal-Erria: revista bascongada, tomo 10, 1884, p. 271.

7 PIRALA CRIADO, A., España, sus monumentos y artes, su naturaleza e historia. Provincias Vascongadas, Barcelona, 1885, p. 130.

8 COLA Y GOITI, J., La ciudad de Vitoria: bajo los puntos de vista artístico, literario y mercantil seguida del indicador del viajero, Vitoria, 1883, 24. COLA Y GOITI, J., «Vitoria artística», Euskal-Erria: revista bascongada, tomo, 15, 1886, p. 246. COLA Y GOITI, J., Guía de Vitoria, Vitoria, 1901, p. 60. COLA Y GOITI, J., "Curiosidades artísticas de Vitoria», Euskal-Erria: revista bascongada, tomo, 55, 1906, p. 192. COLA Y GOITI, J., «Vitoria monumental, la catedral», Vida Vasca, nº 14, 1937, p. 21.

9 TORMO, E., «Un Van Dyck, un Zurbarán, un Villacis (?) y un cuatrocentista florentino inéditos y arrinconados por España», Cultura Española, Nov. IV, 1906, pp. 1437-1440. TORMO, E., «Un Van Dyck», revista Ateneo, 4ª época, año 5, no 41, febrero 1917, pp. 7-9. 
tomo dedicado a la Provincia de Álava realizado por Cristóbal de Castro en 1915 asegura que por la ejecución y por la soberana elegancia de ciertas figuras, se atribuye a Van Dyck ${ }^{11}$. Es sorprendente que el gran cronista de Álava, Eulogio Serdán, no hiciera ninguna referencia a esta pintura ni a las capillas a las que perteneció, centrándose principalmente en algunos aspectos históricos y fundacionales de la colegiata $^{12}$. En 1941 Elías Tormo vuelve a mencionar la obra, ya sin tanta convicción y entusiasmo, pues no responde de la atribución hecha hacía años. Considera, en todo caso, que sería una obra de primera época, hecha en Amberes cuando tendría el pintor entre 16 y 17 años $^{13}$. Estudio clave en el desarrollo crítico de este lienzo es el artículo que Daphne M. Hoffman publicó en 1953 adscribiendo esta pintura al estilo de Gaspar de Crayer ${ }^{14}$. La autora conoció la obra a través de una imagen del Archivo Gudiol de Barcelona. Se hace eco de sus atribuciones a Murillo y Van Dyck ${ }^{15}$ y la considera de Crayer por las grandes similitudes que tiene con la Piedad con San Francisco de Asís de la iglesia de San José de New York.

De esta atribución se hizo eco don José Martínez de Marigorta, canónigo fabriquero y autor de dos pequeñas monografías histórico artísticas sobre la catedral $^{16}$. La profesora Micaela Portilla publicó en 1967 un esclarecedor artículo sobre la misión secreta de Francisco de Galarreta en Flandes. En este estudio se refiere a la pintura como obra atribuida a Gaspar de Crayer y en relación con Francisco o Martín de Galarreta ${ }^{17}$. El Catálogo Monumental de Álava en su apartado correspondiente a la catedral de Santa María, realizado por José María de Azcárate mantiene la atribución a Crayer y considera a Francisco de Galarreta como posible artífice de la llegada de este lienzo a la capilla del Cristo ${ }^{18}$. La atribución quedó aún más consolidada al ser incluida en la monografía que Hans Vlieghe dedicó a Gaspar de Crayer en 1972. En estos dos volúmenes se recoge la mayor parte de la obra de este productivo pintor. Toma como fuente los estudios de Hoffman y Micaela Portilla, considera que se trata de una adaptación libre de composiciones de

10 CARRERAS Y CANDI, F., Geografía del País Vasco-Navarro. Álava. Obispado y Fueros, Barcelona, 1911-1926.

11 CASTRO, C. Catálogo Monumental de España, inventario general de los Monumentos históricos y artísticos de la nación. Provincia de Álava, Madrid, 1915, p. 72.

12 SERDÁN, E., Rincones de la historia de Vitoria, Vitoria, 1914-1924, en Tradiciones Alavesas, tomo II, Vitoria, 1985. SERDÁN, E., Rincones de la historia Vitoriana. La catedral Nueva y la Vieja, Vitoria, 1914-1924. SERDÁN, E., Vitoria, el libro de la ciudad, Vitoria, 1926, en Tradiciones Alavesas, Tomo III, Vitoria, 1985

13 TORMO, E., «El centenario de Van Dyck en la patria de Velázquez», Boletín de la Sociedad Española de Excursiones, Madrid, 1941, p. 155 y 164.

14 HOFFMAN, D. H., «An altarpiece restored to its author and to the altar». G. B. Arts., 1953, I, p. 99.

15 Hoffman toma este dato de la versión inglesa (1913) y castellana (1924) de la guía de viajes: BAEDEKER, K., Spanien und Portugal, Leipzig, 1897 (5 $5^{\mathrm{a}}$ ed. 1929).

${ }^{16}$ MARTÍNEZ DE MARIGORTA, J., En el camino de Santiago. Catedral de Santa María de Vitoria (1862-1962), Vitoria, 1964, p. 46. MARTÍNEZ DE MARIGORTA, J., Las dos catedrales, Vitoria, 1969.

17 PORTILLA, M., «Misión secreta de un alavés en Flandes. Don Francisco de Galarreta Ocáriz (año 1643)», Boletín Sancho el Sabio, año XI, Tomo XI, 1967, p. 46.

${ }_{18}$ AZCÁRATE, J. M., "Catedral de Santa María» en VV.AA., Catálogo Monumental de la Diócesis de Vitoria, Vitoria, 1968, p. 107. 
Lamentación sobre Cristo muerto de la catedral de Santa María de Vitoria-Gasteiz...

Van Dyck y que se podría suponer que fue enviada por Francisco de Galarreta en 1643, año en el que pudo conocer a Gaspar de Crayer $^{19}$.

A partir de los años 80 esta pintura ha aparecido nombrada en infinidad de trabajos de investigación y divulgación de ámbito local o provincial ${ }^{20}$. En todos ellos se toma como referencia algunos de los estudios hasta ahora citados considerando que se trata de una obra atribuida a Gaspar de Crayer y vinculada a Francisco de Galarreta. Mención especial merece el artículo dedicado a la restauración del cuadro llevado a cabo por Cristina Aransay y Marina López en el que, gracias a los análisis de laboratorio y estudios complementarios, se desvelan todos los secretos técnicos de esta obra ${ }^{21}$. Es también digno de destacar por su contenido y valor didáctico el folleto de divulgación realizado por Itziar Aginagalde y Aintzane Erkizia en el marco del Museo Diocesano de Arte Sacro. Nuestro último trabajo dedicado a la fundación y patronato de los Alday y Galarreta en la catedral de Santa María y el vaciado documental que realicé por encargo del Servicio de Restauraciones de la Diputación Foral de Álava en el momento de la restauración del cuadro nos han animado a llevar a cabo este trabajo de ordenación e investigación de todos los datos que por el momento conocemos de esta enigmática obra ${ }^{22}$.

Desde su llegada a Vitoria esta pintura ha estado vinculada a los hermanos Galarreta y a la capilla del Cristo que fundaron y dotaron en la catedral de Santa María de Vitoria-Gasteiz (Fig. 2). Francisco de Galarreta y su hermano Martín formaban parte de la nobleza rural alavesa. Eran naturales por parte de padre de la casa solar de Ocáriz en Galarreta y por línea materna de la casa torre de Echávarri Zárate en el valle de Zuia23. Francisco de Galarreta (1602-1659) se abrió camino en la corte desde muy joven. Seguramente se formó en alguna universidad castellana para pasar a ocupar algún puesto de representación al servicio de la corona.

19 VLIEGHE, H., Gaspar de Crayer, sa vie et ses oeuvres, tomo I, Bruxelles, 1972, p. 172, fig. 116.

20 Entre otras publicaciones quiero destacar: ANDRÉS ORDAX, S., «Evolución artística» en Historia de una ciudad. Vitoria, tomo I, Vitoria, 1977, p. 138. OCHOA AXPE, M., «Alaveses universales», en Álava en sus manos, 2, Vitoria-Gasteiz, 1983, p. 87. AA.VV., «Iglesia de Santa María de Vitoria-Gasteiz», en Monumentos nacionales de Euskadi, Vitoria, 1985, p. 373. MARTÍNEZ DE SALINAS, F.; VÉLEZ CHAURRI, J., Vitoria Barroca, Vitoria, 1986. ANDRÉS ORDAX, S., «Arte» en Tierras de España. País Vasco. Madrid, 1987, p. 287. GARCÍA DÍEZ, J. A., La pintura en Álava, Vitoria, 1990. TABAR, F., Barroco importado en Álava, Vitoria, 1995, p. 131. VÉLEZ CHAURRI, J. J., «Barroco», en Vitoria Gasteiz en el arte, Vitoria, 1997, pp. 408-409. BARTOLOMÉ GARCÍA, F. R., El arte Barroco en Álava, Vitoria, 1999, p. 70. TABAR ANITUA, F., «Pintura y escultura de los siglos XVI y XVII en Álava», en Museos en Álava, un patrimonio desconocido, Vitoria, 2000, p. 34. TABAR ANITUA, F., «La pintura del barroco en Euskal Herria. Arte local e importado», Ondare, 19, 2000, pp. 144-145. VÉLEZ CHAURRI, J. J.; ECHEVERRÍA GOÑI, P. L., «Pintura barroca con vinculación histórica al País Vasco», en Luces del Barroco, Pintura y escultura del siglo XVII en España, Vitoria, 2002, pp. 26-27.

21 ARANSAY SAURA, C.; LÓPEZ VILLANUEVA, M., «Restauración de la pintura Lamentación sobre Cristo Muerto atribuido a Gaspar de Crayer», en Micaela Portilla. Omenaldia. Homenaje. In Memoriam. Actas de las Jornadas Congresuales, Vitoria, 2007, pp. 340-347.

22 BARTOLOMÉ GARCÍA, F. R., «Fundación y patronato de los Alday y Galarreta. Las capillas de San Prudencio y Santo Cristo en la catedral de Santa María de Vitoria-Gasteiz», Ars Bilduma. Revista del Dpto. de Historia del Arte y Música de la U.P.V., no 0, (2010), pp. 14-39.

${ }^{23}$ PORTILLA, M., «Misión secreta de un alavés en Flandes. Don Francisco de Galarreta Ocáriz (año 1643)», Boletín Sancho el Sabio, año XI, Tomo XI, 1967, pp. 5-50. 
Su ascenso debió ser meteórico, pues en 1636, con treinta y cuatro años, ya estaba ejerciendo labores de diplomacia en Flandes. Al parecer, sirvió primero como secretario de la embajada española en París, para pasar posteriormente a trabajar como secretario del príncipe Tomás de Saboya y alcanzar el puesto de Secretario de Estado y de Guerra en Flandes durante los años 1636-38 y 1644-48. Le tocaron misiones de negociación muy delicadas en un momento de grandes dificultades en la política exterior española ${ }^{24}$. De su labor como embajador en Flandes nació su matrimonio con Claudia de Lira, cuya familia estuvo vinculada a la política internacional. No tuvo descendencia legítima, por lo que el heredero de la mayor parte sus bienes fue su hermano Martín de Galarreta y la usufructuaria su mujer, Claudia de Lira. Murió en Madrid en 1659 y fue enterrado en el convento de San Francisco, en la capilla que disponía don Francisco de Lira, hermano de su esposa, con la condición de que fuera trasladado a su capilla del Cristo en la colegiata de Vitoria en cuanto fuera posible.

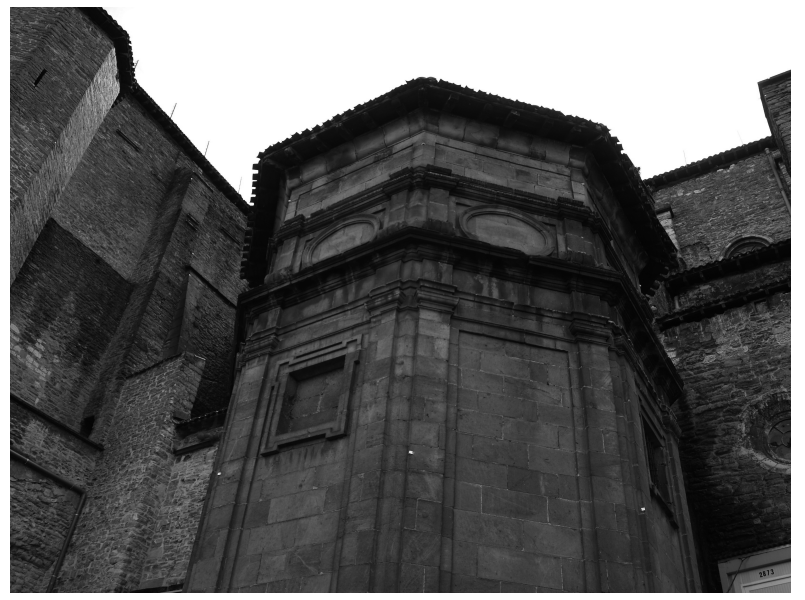

Fig. 2. Capilla de Santo Cristo. Vitoria-Gasteiz. Catedral de Santa María.

Martín de Galarreta (1606-1673) siguió los pasos trazados por su hermano mayor. Una vez formado debió ser acomodado en la corte, en distintos puestos de la administración, hasta que fue nombrado Secretario de Estado y Guerra en Flandes y miembro del Consejo del Rey. En Flandes permaneció durante catorce años, entre 1655 y 1669, y reconoce haber estado al servicio real durante cuarenta años. Por su trabajo vivió a caballo entre Flandes y Madrid, aunque es en esta ciudad donde tuvo instalada su casa, bien amueblada y con una buena colección de pin-

24 PORTILLA, M., Op. Cit., ECHEVARRÍA, M. A., Flandes y la monarquía hispánica 1500-1713, Madrid, 1998, pp. 138, 311, 312, 344, 396, 412. ESCUDERO, J. A., Los secretarios de Estado y del despacho, Madrid, 1976, pp. 272 y ss. ISRAEL, J. I., La república holandesa y el mundo hispánico 16001661, Madrid, 1997, pp. 292-293. VERMIER, R., En estado de guerra Felipe IV y Flandes 1629-1648, Córdoba, 2006, pp. 97, 191, 268, 269, 272, 273, 275, 278. BARTOLOMÉ GARCíA, F. R., Op. cit. (2010), pp. 14-39. 
turas. El 10 de octubre de 1672 redactaba su testamento y un año después moría siendo enterrado en el convento de San Francisco de Madrid en la capilla de su amigo Manuel de Tera. El funeral también se celebró en Vitoria, en la capilla del Cristo que según sus propias palabras «yo la hice fabricar y poner en el estado que al presente está con el dinero que para este efecto me dejó el dicho mi hermano». Sus restos se llevaron a esta capilla, en la colegiata de Vitoria, el día 9 de octubre de 1675. Buena parte de sus bienes los destinó al mantenimiento de tres capellanías que había fundado en su capilla del Cristo. Las dotó con doscientos ducados de renta a cada una y las repartió de la siguiente manera: una para el canónigo magistral de púlpito más viejo de la colegiata, y las otras dos para sus parientes más cercanos. En 1670 entregaba 4000 reales de plata para que con sus réditos se asistiera la fundación con antífonas las vísperas de los días de la cruz de mayo y septiembre y una misa con canto de órgano ${ }^{25}$. Otra parte de sus bienes dejó a su criado José Lebent, un joven flamenco con el que había convivido buena parte de su vida, y a quien quiso acomodar con una renta de 200 ducados al año y facilitar la vuelta a su país ${ }^{26}$.

Fue Martín de Galarreta el encargado de llevar a cabo la construcción de la capilla en la colegiata de Vitoria; la dotó económicamente y la vistió con los ornamentos necesarios. Es de planta octogonal cubierta por una cúpula de media naranja que en su origen debió tener linterna vista al exterior (Fig. 2). Está situada en el tercer tramo de la nave del Evangelio y es anexa a la de San Prudencio, la cual comparte el mismo patronato. Esto es debido a que Pedro López de Alday, fundador de la capilla de San Prudencio, cedió su patronato a su sobrino Baltasar de Echávarri pasando posteriormente a Ochanda de Echávarri, madre de Francisco y Martín de Galarreta. La capilla del Santo Cristo se contrataba el 9 de enero de 1661 con el cantero guipuzcoano Pedro de Amezti. Al parecer debió participar con Juan de Ansola Ibaiguren, un conocido cantero de Eibar. Estos maestros se limitaron a construir la capilla, pues la traza había sido enviada desde Flandes por Martín de Galarreta que por esas fechas ejercía como Secretario de Estado ${ }^{27}$. En 1663 ya estaba terminada la obra pero algunos años más tarde comienzan los problemas con las filtraciones de agua. Su reparación se contrató el 17 de octubre de 1674 con el acreditado cantero cántabro Juan Setién Agüero, y todo lo relativo a la carpintería en 1675 con Pedro de Otalora y Martín de Urteaga. En esta intervención parece que se desmochó la linterna y se hizo un nuevo tejado para evitar la entrada de las aguas llovedizas ${ }^{28}$.

Terminada la construcción en 1663 fue Martín de Galarreta, según él mismo confiesa, el encargado de proporcionar a la capilla las rentas para su manteni-

25 AHDV-GEAH. Acuerdos del cabildo (1661-1682), caja 199-2, fol. 182. «Entregó 34 doblones de a ocho y uno de a cuatro en oro y se le devolvió un real de a dos de plata los cual montan los 4000 reales de plata y otorgó el cabildo carta de pago y recibo ante Juan de Amesti».

${ }^{26}$ BARTOLOMÉ GARCÍA, F. R., Op. cit. (2010), pp. 14-39.

27 BARTOLOMÉ GARCÍA, F. R., Op. cit. (2010), pp. 14-39.

28 AZCÁRATE, J. M., Op. Cit., p. 118. BARTOLOMÉ GARCÍA, F. R., Op. cit. (2010), pp. 14-39. 
miento y de dotarla de todos los ornamentos necesarios. Es lógico pensar que fuera también en esta fecha cuando se colocó el lienzo de la Lamentación y el resto de las obras que decoraban la capilla del Cristo. No hay duda de que esta obra no fue hecha ex profeso para la capilla, pues sus dimensiones sobrepasan el testero de la misma, por lo que tuvo que ser ubicada en el muro este de la de San Prudencio, sobre un pequeño retablo dedicado a este santo. Aún es un misterio quién de los dos hermanos encargó o adquirió la obra. Hasta el momento siempre se ha citado, sin la debida certeza, a Francisco de Galarreta como el responsable del encargo, y es probable que nunca tengamos la evidencia de quién de los dos hermanos fue el promotor de su adquisición. La profesora Micaela Portilla propone varias posibilidades perfectamente asumibles; que Francisco de Galarreta comprara el cuadro en alguna de sus dos estancias en Flandes o que fuera adquirida por su hermano Martín, quien pudo seguir manteniendo la amistad con el pintor Gaspar de Crayer.

No obstante, hay algunos aspectos que también debemos valorar a la hora de analizar la adquisición y posesión de la misma. Uno de ellos es la permanencia de estos dos hermanos en Flandes: Francisco estuvo aproximadamente siete años como Secretario de Estado y Guerra, en momentos de gran conflictividad política, mientras que Martín permaneció durante catorce años, en tiempos menos convulsos, lo que le pudo permitir adquirir obras con las que engalanar su casa de Madrid o su futura capilla funeraria. Además, tras la muerte de su hermano Francisco en 1659, quedaba muy bien situado económicamente al ser su heredero universal.

No tenemos constancia del mobiliario y obras de arte que Francisco disponía en sus casas. Tan sólo sabemos, según indica la profesora Micaela, que en Flandes poseía una casa alhajada enriquecida, con reposteros y probablemente con lienzos y tapices ${ }^{29}$. Por su parte, Martín de Galarreta poseía en su casa madrileña una digna colección de pinturas. En concreto tenía «seis países de Flandes», además de numerosos paisajes con figuras, cacerías y otras escenas ${ }^{30}$. Disponía

29 PORTILlA, M., Op. Cit., p. 46. BARTOlOMÉ GARCÍA, F. R., Op. cit. (2010), pp. 14-39. Esos catorce reposteros procedían de Bruselas, eran de seda y lana, tenían el escudo familiar y fueron heredados por Martín de Galarreta, y regalados en 1674 al convento de San Francisco de Vitoria.

30 Seis países de Flandes con sus molduras de pino negro y relieves dorados (cuatro iguales y seis algo mayores) / Cinco países grandes con figuras pequeñas de hombres y mujeres / Un lienzo en el que está pintada la plaza en una fiesta de toros con su marco negro / Otro lienzo de vara y media de caída y dos de ancho en la que esta pintada la tela y la fuente segoviana / Cuatro países de vara y tres cuartos de caída y dos y media de ancho con diferentes figuras de hombres y mujeres pequeñas / Otro país de dos varas de ancho y dos de caída con unos cazadores y perros / Otro país de cerca de dos varas de caída y vara y cuarto de ancho con figuras pequeñas de hombres y mujeres con marcos negros / Un paisaje de una vara de caída y vara y media de ancho con unos ermitaños y una ermita con marco negro / Dos países iguales de vara y media de ancho y una de caída con molduras negras y relieves dorados / Dos países iguales de vara de ancho y media de caída cada una con sus molduras negras / Otro paisaje con la portada de una casa con su moldura negra de media vara de caída y tres cuartas de ancho. Otro paisaje de vara y media de ancho y vara y media de caída con figuras muy pequeñas y marco negro / Otro paisaje del mismo tamaño con figuras pequeñas y una casería. 
de siete pinturas religiosas con diversos temas ${ }^{31}$, de todas ellas destacan dos, que a juzgar por la descripción, probablemente fueran flamencas, pues estaban «cercadas de flores», algo muy habitual en los talleres de Amberes del siglo XVII'22. Una de ellas, valorada en 2600 reales y dedicada a San Ignacio de Loyola hablando con Nuestra Señora y el Padre Eterno fue remitida a Vitoria y finalmente quedó en manos de doña Magdalena de Nanclares, abadesa del convento de Salvatierra y testamentaria de Martín de Galarreta. También contaba con un buen conjunto de retratos, dos de Felipe IV, y otros de altos funcionarios de los Países Bajos, del archiduque Leopoldo, del conde de Fuensaldaña y de Juan José de Austria, hijo bastardo de Felipe IV ${ }^{33}$. Los tres gobernaron en los Países Bajos y por lo tanto fueron superiores de Francisco y Martín de Galarreta. El archiduque Leopoldo Guillermo de Habsburgo, además de gobernador de Flandes, fue un gran amante del arte, mecenas y coleccionista, como lo demuestra la colección de pinturas que regaló a Felipe IV. Es además el protagonista del famoso cuadro de David Teniers El archiduque Leopoldo Guillermo en su galería de pinturas en Bruselas ${ }^{34}$, una obra en la que junto al archiduque están retratados el propio pintor y, curiosamente, el conde de Fuensaldaña, don Alonso Pérez de Vivero. Este destacado funcionario de la corte de Bruselas, del que, como hemos visto, también guarda un retrato Martín de Galarreta, fue un gran amante del arte, pues encargó a Teniers la compra de varias pinturas en Londres para su colección particular ${ }^{35}$. Además fundó el convento de Fuensaldaña del que fue benefactor y al que envió importantes lienzos. Fue por lo tanto en este ambiente propicio al coleccionismo y al amor por el arte en el que se desenvolvió este personaje.

${ }^{31}$ Un paisaje con Nuestra Señora, San José con el Niño y un ángel de vara y cuarta de ancho y caída con moldura negra y relieve dorado / Otro del mismo tamaño con la misma moldura con una Ángel hablando con una mujer / Otra del mismo tamaño con la misma moldura con Nuestra Señora y la Magdalena cuando se apareció en el huerto / Otra del mismo tamaño con la misma moldura de San Jerónimo penitente / Una pintura de Nuestra Señora con el Niño en brazos de dos varas de caída y vara y media de ancho con marco negro y relieve dorado.

32 Una lámina con Nuestra Señora, San José y Santa Teresa echándola un collar cercada de flores y moldura de ébano de vara de caída y media de ancho / Otra lámina con San Ignacio de Loyola hablando con $\mathrm{N}^{\mathrm{a}} \mathrm{S}^{\mathrm{a}}$ y el padre eterno encima cercado por serafines y unas flores alrededor de medida vara de caída y poco menos de ancho y marco dorado.

${ }_{33}$ AHDV-GEHA. Caja 119-8. s.f. Un retrato del Rey Felipe IV de una vara de caída y poco menos de ancho y relieve dorado / Otro retrato de Juan de Austria con su moldura negra / Otro retrato del conde de Fuensaldaña con su moldura negra / Otro retrato del Archiduque Leopoldo con moldura negra / Otro retrato de Felipe IV con su moldura negra. Las pinturas fueron tasadas por el pintor "Gil Frederique». El inventario se realizaba el día 5 de octubre de 1673. La almoneda se llevo a cabo el 16 y 20 de octubre del mismo año.

34 David Teniers the Younger, cat. exp., Gante, Snoeck-Ducaju and Zoon, 1991. DAVIDSON, J. P., David Teniers the Younger, Boulder, Colorado, Westview Press, 1979, pp. 21 y 28. DÍAZ PADRÓN, M., Catálogo de pinturas. Escuela flamenca, siglo XVII, Madrid, Museo del Prado y Patronato Nacional de Museos, 1975, pp. 404 y ss. ORS, E. d', Tres horas en el Museo del Prado, Madrid, Ediciones Españolas, 1941, p. 179. SCHÜTZ, K., La peinture flamande au Kunsthistorisches Museum de Vienne, Amberes, Fonds Mercator, 1987, p. 208.

${ }_{35}$ VERGARA, A., «The count of Fuensaldaña and D. Teniers. Their purchases in London after the civil war», The Burlington Magazine, Londres, 1989, p. 27. 
Por sus propias palabras sabemos que Martín de Galarreta se había encargado de dotar a la capilla del Cristo de todos los ornamentos necesarios. Además de los objetos básicos para la consagración, mandó hacer en su testamento seis candeleros de varios tamaños para colocarlos sobre el altar del Santo Cristo durante las festividades. El encargado de materializar esta petición fue José Lebent, fiel y amado criado de Martín de Galarreta. Los encargó en Madrid en 1674, al platero Andrés Sevillano «ADS/SEVI» por 6801 reales $^{36}$. Fueron contrastados por Manuel Mayers Caramuel, contraste de oro y plata de Felipe IV y Carlos II. A su llegada a Vitoria fueron grabados por el platero Melchor Ortiz de Zárate con la siguiente inscripción «SOI DE D. MARTIN DE GALARRETA I OCARIZ SRIO DEL $R E \mid \gg{ }^{37}$. Se conservan cinco y son piezas puristas de gran sobriedad y elegancia, siguiendo la tipología habitual del siglo XVII. Todo esto demuestra que la implicación de Martín de Galarreta con la capilla fue absoluta. No sólo llevó a cabo la última voluntad de su hermano fundando esta capilla, sino que se encargó de todo lo relativo a su construcción, mantenimiento y ornato. No es por lo tanto descabellado pensar que fuera Martín de Galarreta el encargado de adquirir y colocar la pintura de la Lamentación sobre Cristo muerto en la capilla familiar. No hay duda que con esta obra, a los pies de su cripta familiar, quisieron emular a los grandes hombres de su tiempo. Es curioso recordar que el propio Van Dyck fue enterrado en un beaterio de Amberes presidido por un Llanto sobre Cristo muerto.

Este cuadro permaneció casi olvidado hasta el siglo XVIII. En concreto, el 12 de mayo de 1785 los patronos de la fundación de los Galarreta aprueban la idea de trasladar el lienzo de la capilla de San Prudencio a la sacristía o a otro lugar destacado de la colegiata (Fig. 3). El único requisito solicitado era que se pusiera una tarjeta donde se expresara la pertenecía de la pintura ${ }^{38}$. Esta repentina preocupación por el cuadro se debió a la presencia en Vitoria de los hermanos Robert y Pierre Michel y del pintor Antón Raphael Mengs ${ }^{39}$. De Roberto Michel sabemos que debió tener alguna relación con esta ciudad pues estuvo casado con Rosa Ballerna y cuatro meses antes de su muerte manifestaba que los aires de Álava le habían mejorado un poco de sus dolencias ${ }^{40}$. Rosa Ballerna era tía del conocido platero y broncista José Ballerna, oriundo de Vitoria, aunque con taller en Madrid ${ }^{41}$.

36 AZCÁRATE, J. M., Op. cit. p. 110. MARTÍN VAQUERO, R., La platería en la diócesis de Vitoria (1350-1650), Vitoria, 2000, p. 603, pieza 374. BARTOLOMÉ GARCÍA, F. R., Op. cit. (2010), pp. 14-39.

37 BARTOLOMÉ GARCIA, F. R., Op. cit. (2010), pp. 14-39.

38 ARANSAY SAURA, C.; LÓPEZ VILLANUEVA, M., «Restauración de la pintura Lamentación sobre Cristo Muerto atribuido a Gaspar de Crayer», en Micaela Portilla. Omenaldia. Homenaje. In Memoriam. Actas de las Jornadas Congresuales, Vitoria, 2007, pp. 340-347.

39 Documento cedido por la familia Eseverri a la Fundación Catedral Santa María.

40 SÁNCHEZ CANTÓN, F. J., «Roberto Michel, escultor del siglo XVIII» Boletín de la Sociedad Española de Excursiones, XXV (1917), pp. 4-6. LORENTE ARÉVALO, C., TASCÓN GÁRATE, C. Mํa ., «Nuevas aportaciones a la biografía del escultor Roberto Michel», Anales de la Historia del Arte, n 5, (1995), pp. 225-235. TABAR, F., Escultura académica en Álava, la escuela de Madrid del siglo XVIII, Vitoria, 2008, pp. 131-138.

41 MARTÍN VAQUERO, R., «En torno a Rafael de Ballerna, un desconocido platero vitoriano: su testamento», Ondare, 18, 1999, pp. 149-170. MARTíN VAQUERO, R., «La real escuela de platería Martínez de Madrid y su relación con la escuela de dibujo en Álava», Ondare, 21, 2002, pp. 275-291. 
Curiosamente su hermana Bárbara Ballerna se había casado con Pedro Michel. Hay que recordar que el busto de Carlos III encargado a Roberto Michel por la Real Sociedad Bascongada de los Amigos del País para su sede alavesa está firmado en 1785, año en el que debió pasar una temporada en estas tierras. En el caso del «pintor de su S. M. caballero Mong (Mengs)» no sabemos cuál fue el motivo de viajar a Vitoria, pero probablemente pasara por esta ciudad para visitar a los Michel, con los que debió tener amistad, pues en 1775 apoyaba la candidatura de Roberto Michel para conseguir el puesto de escultor de Cámara de Carlos III ${ }^{42}$. Sabemos que para «descubrir y observar las preciosidades de la mencionada pintura», Mengs tuvo que usar luz artificial y, con miedo, subirse a la mesa de altar. Tras el redescubrimiento de esta obra por parte de estos ilustres viajeros se aprovecho para limpiarla y recuperar toda su belleza, pues aparte de la suciedad acumulada tenía algunas quemaduras poco importantes y en «partes menos principales, pero siempre sensibles». Desconocemos quien llevó a cabo esta labor de limpieza y pequeñas reparaciones pero es probable que lo realizara el conocido pintor José López de Torre, pues en las cuentas de 1786 recibía un pago ${ }^{43}$.

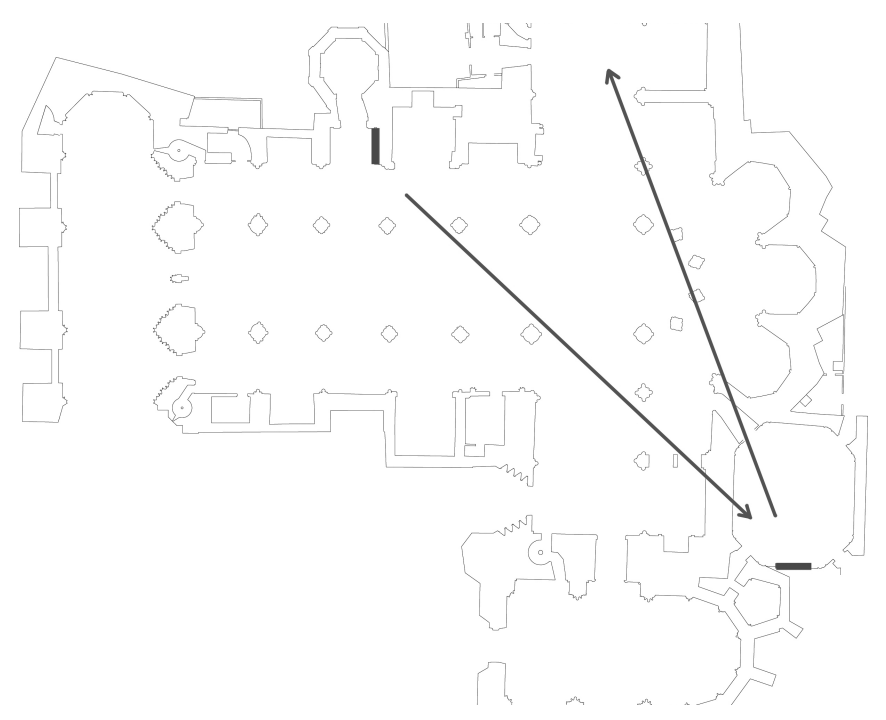

Fig. 3. Planta con las ubicaciones del lienzo de la Lamentación.

El 29 de mayo de 1785 el cura de la parroquia presenta ante la junta del cabildo la propuesta de traslado a la sacristía hecha por los patronos de la fundación de don Martín de Galarreta ${ }^{44}$. Esta decisión se tomó tras haber comprobado que se trataba de una «de las efigies mas sobresalientes y de mayor primor» de la colegiata, y que en el sitio en el que se encontraba no se apreciaba su belleza dada «la oscuridad

42 LORENTE ARÉVALO, C., TASCÓN GÁRATE, C. Ma․, Op. Cit. p. 228.

43 AHDV-GEAH. Libro 8841-1. Cuentas 1786-87, fol. $281 \mathrm{v}$.

44 AHDV-GEAH. Libro de decretos 218-2. s. f. 
del paraje». Se pensó que el lugar más apropiado para su mayor lucimiento era la sacristía, por ser uno de los espacios más iluminados de la iglesia. El 10 de noviembre del mismo año el cuadro pasó «al paño de hacia medio día» de la sacristía, sobre el respaldar, con un marco nuevo y un remate al que posteriormente se añadió una cortina con cenefa. Debió ser este el momento elegido para colocar la inscripción de propiedad que aún se puede leer en el reverso del lienzo ${ }^{45}$.

Este remate se conserva parcialmente y consta de un entablamento con el friso tallado con un motivo encadenado. Está coronado por un tondo circular con lazada dorada, listado en su interior, que descansa en un basamento rectangular decorado con doce gallones. El marco es plenamente neoclásico en la línea del estilo Carlos IV, con la entrecalle tallada con motivos geométricos, a modo de cintas de lacería entrelazadas y rosetas intercaladas. Su perfil exterior lo recorre un cordón helicoidal y el interior hojas de agua ${ }^{46}$. A los pies del lienzo y sobre el respaldar se colocaron dos niños semidesnudos cubiertos únicamente por un sencillo paño de pureza. Están sentados con las piernas cruzadas y los brazos abiertos, y portan dos símbolos de la Pasión, lanza y caña con esponja. Probablemente fueran realizados por los Santeros de Payueta, en concreto por Alejandro o Inocencio de Valdivielso. El dorado y estofado corrió a cargo de Pablo Jiménez, por lo que le pagaron 700 reales, y 100 más como gratificación por lo satisfechos que habían quedado tanto el patronato como el público. El espacio libre que este lienzo había dejado en la capilla de San Prudencio fue ocupado por una copia del Entierro de Cristo de Caravaggio (191 x 214). Esta obra había sido cedida en 1785 por el Abad de la colegiata y es una modesta copia antigua de la citada obra. Se encuentra bastante retocada, probablemente hacia 1883, año en el que se pagaron 300 pts por restaurar «el cuadro de la Piedad que se venera en la capilla» de San Prudencio ${ }^{47}$.

La colocación de la Lamentación en su nuevo emplazamiento generó ciertas controversias entre los miembros del cabildo, pues rompía la simetría del respaldar y de la propia sacristía. La solución pasaba por «mudarlo a otro paraje» o levantarlo más para que no interfiriera tanto sobre la simetría del mueble ${ }^{48}$. Los proble-

45 «Esta pintura y marco es de el Patro-/nato Galarreta quien dispuso el co-/locarla en esta Sachristia a fin de $\mathrm{q}(\mathrm{ue}) /$ se gozase en ella el Primor de la Pintura/ lo q(ue) no sucedia en su Capilla de S(an) Pruden-/cio...»

${ }^{46}$ El bastidor original era fijo y rígido sin cuñas tensoras tan solo reforzado por listones. Estaba realizado en pino salgareño también conocido como pino laricio y pino negral. ARANSAY SAURA, C.; LÓPEZ VILLANUEVA, M., Op. Cit. p. 342.

${ }^{47}$ MARTÍNEZ DE MARIGORTA, J., La catedral de Santa María de Vitoria, Vitoria, 1964. AZCÁRATE, J. M., Op. cit. p. 108. PORTILLA, M., Op. Cit., p. 46. TABAR, F., Barroco importado..., p. 133. ARANSAY SAURA, C.; LÓPEZ VILLANUEVA, M., Op. Cit. p. 341. BARTOLOMÉ GARCíA, F. R., Op. cit. (2010), pp. 14-39. AHDV-GEAH. Libro 8841-1. Documentación Eseverri. s.f. Fue restaurado por el pintor Danquien y también intervino el carpintero Julián Medina. «...y las debidas gracias al señor Abad por su libertad de franquear una pintura, muy decente, de proporcionado tamaño y del mismo ministerio que la que va explicada para poner en lugar de ella y en el del altar de San Prudencio donde permanezca mientras la otra no vuelva al mismo sitio".

${ }^{48}$ AHDV-GEAH. Libro de decretos 218-2. s. f. 
mas llegaron más tarde, cuando los patronos de la capilla de los Galarreta exigen mediante un escrito fechado el 28 de junio de 1842 que se coloque una tarjeta de propiedad junto al referido cuadro, «con la expresión conducente a perpetuar la memoria de su legítimo Dueño», como se había concretado antes de su traslado a la sacristía ${ }^{49}$. No parece que esta solicitud fuera llevada a cabo y el 10 de diciembre de 1865 el nuevo patrono de la capilla de San Prudencio, don Julián de Echaguibel exige el retorno del cuadro a su lugar de origen. Desconocemos el alcance de esta petición, pero lo más probable es que el lienzo no fuera trasladado a su capilla permaneciendo en esta sacristía hasta la intervención llevada a cabo por Manuel Lorente en la década de lo sesenta (Fig. 3). En 1965 se retiró todo este complemento decorativo y se trasladó al hastial del lado derecho del crucero. Allí permaneció hasta que en 1999 pasara al recién creado Museo Diocesano de Arte Sacro $^{50}$.

El lienzo presenta el momento inmediato a la muerte de Cristo y su descendimiento de la Cruz. En este caso está representado por cuatro personajes principales y un reducido cortejo de ángeles lastimeros. El protagonista principal es Cristo, sentado en el suelo y sostenido por la Virgen. Está muerto, con el cuerpo lívido, contusionado y algo hinchado como resultado del doloroso martirio recibido (Fig. 4). Aún se advierten restos de sangre que brotan de algunas de sus heridas. No es mucha ya, pues están lavando el cuerpo para darle sepultura. Sólo se advierten leves regueros en la herida del costado derecho, producida por la lanzada, y en la cabeza, con varias heridas en la frente debidas a las punzantes espinas de la corona, de las que todavía conserva una clavada con crudeza en la carne. De estas lesiones frontales manan finos hilos de sangre que se acumulan en el hueco de la clavícula, como si de cálices sagrados se trataran. No se opta por un hombre demacrado y endeble sino por un joven corpulento y de buena musculatura en la línea de los grandes pintores flamencos del barroco. Se le representa semidesnudo, tan sólo cubierto por un improvisado paño de pureza y recostado sobre una sábana blanca que sostiene la Virgen y le servirá de mortaja. La inmaculada blancura de estos lienzos se ve levemente interrumpida por restos de sangre que sonrosan su candor.

El tema sirve de disculpa para indagar en los retos que un estudio anatómico tiene para cualquier artista. Está resuelto con enorme naturalismo prestando atención a los más insignificantes detalles de la anatomía humana. Se diferencian muy bien las zonas blandas de las más musculadas, las venas, los golpes, los pliegues y los pequeños detalles que solo un pintor de primera línea es capaz de definir con precisión. El rostro resulta de primorosa verosimilitud; expresa el dolor de todo el martirio recibido y la serena paz alcanzada tras la muerte. Tiene la cabeza

49 La tarjeta debía haberse colocado «a su lado o inmediación».

50 ARANSAY SAURA, C.; LÓPEZ VILLANUEVA, M., Op. Cit. p. 341. Fue restaurado por el Servicio de Restauraciones de la Diputación Foral de Álava en colaboración con la Fundación Catedral Santa María (2003-2005). 
ladeada hacia la derecha, apoyada sobre su hombro y sobre el brazo de la Virgen. Los ojos cerrados, pero hinchados y desencajados por el sufrimiento recibido; la nariz recta y prominente, y los labios inflados y amoratados como es habitual en los cadáveres. La frente herida y sangrante con una espina clavada como muestra de martirio, detalle habitual entre algunos pintores flamencos. Tiene alborotada melena y barba poblada de tono pajizo, lo que contrasta con su cuerpo absolutamente lampiño. Un halo de luz celestial ilumina su rostro en referencia a su carácter divino.

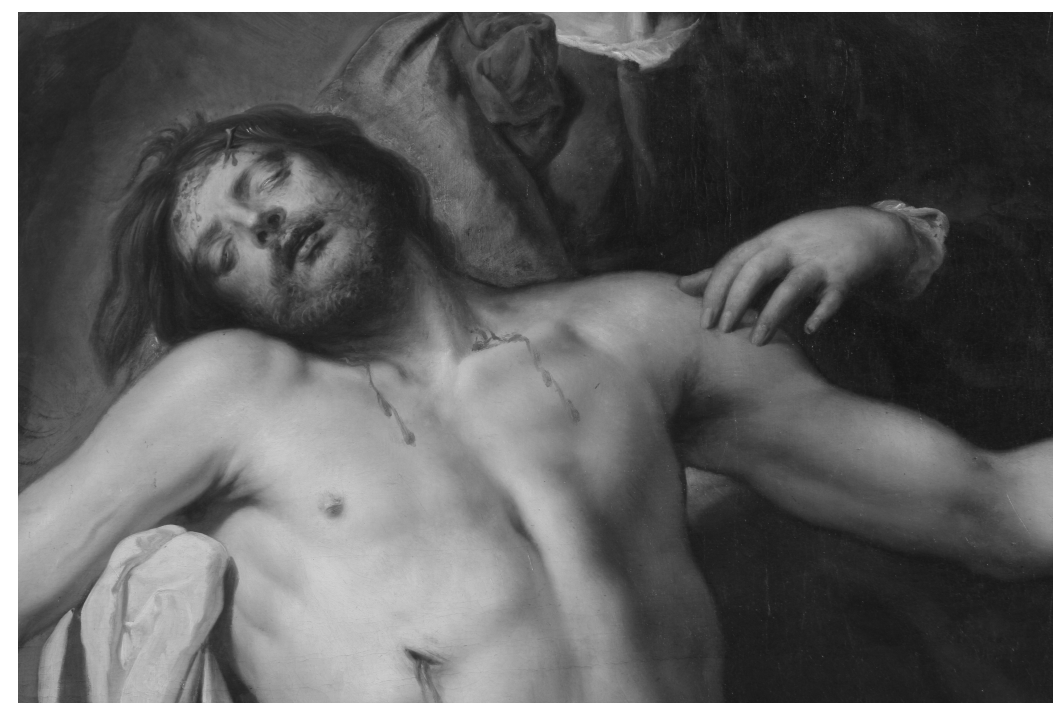

Fig. 4. Lamentación sobre Cristo muerto. Detalle de Cristo.

La Virgen sirve de respaldo ideológico y moral al tema. Está sentada y sujeta el cuerpo inerte de su Hijo con su mano y pierna derecha, oculta por un inmaculado sudario, mientras que con la mano izquierda acaricia levemente su hombro. Viste con sobriedad, con una túnica azul oscura que deja ver en cuello y mangas una sutil camisola blanca. Se acompaña de un ampuloso manto azul cielo que sirve de respaldo a Cristo y cubre su melena con un velo, en referencia a su estado de casada. Su rostro es excepcional, se muestra sereno pero lleno de una emoción contenida que enmascara levemente el inmenso dolor que supuso la pérdida de su Hijo. Es de cabeza recta y angulosa, apoyada en un poderoso y musculado cuello de recuerdo manierista. Su palidez manifiesta su estado anímico, refrendado por su emocionada mirada hacia el firmamento, con enormes ojos vidriosos que no acaban de romper en llanto (Fig. 5). Su emotivo gesto se ayuda de párpados hinchados y expresivas cejas. Es de nariz algo chata, con boca pequeña y algo entreabierta, pero bien perfilada por sus carnosos labios. 


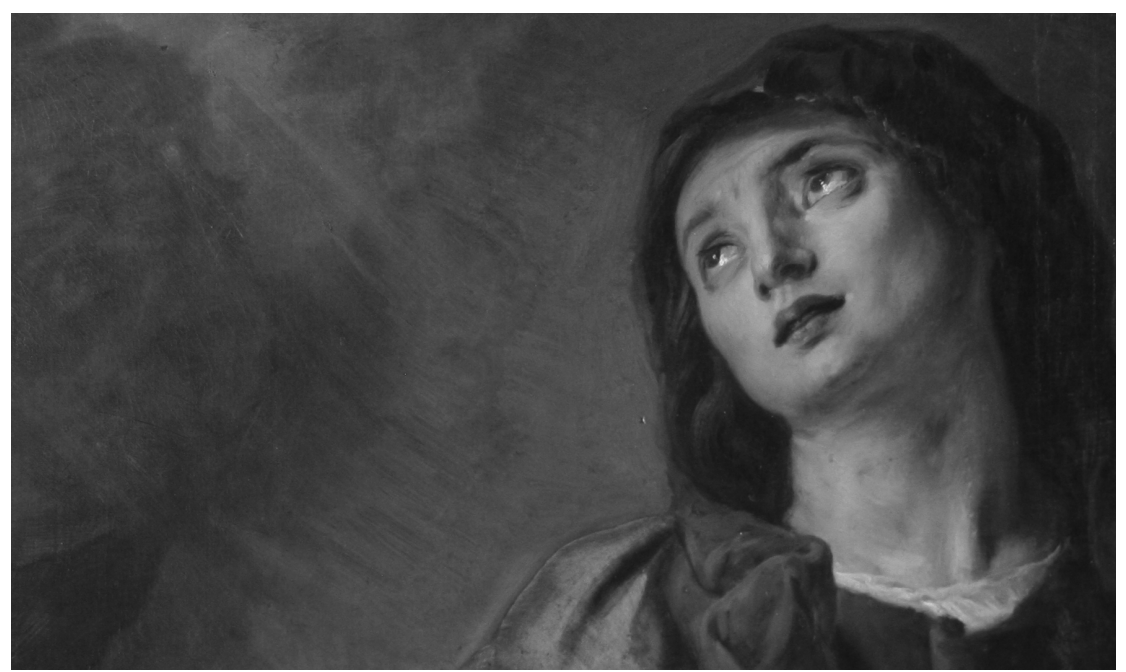

Fig. 5. Lamentación sobre Cristo muerto. Detalle de la Virgen.

En primer plano, junto a los pies de Cristo, se sitúa la Magdalena, pues fue ella la encargada de ungirlos con el tarro de ungüento. Está arrodillada, en posición orante y es una mujer joven y bella, de cierta corpulencia y marcada impronta norteña (Fig. 6). Lleva un lujoso vestido de seda que recuerda su origen de cortesana ya arrepentida. Es de color vino y de aspecto airoso, con ampulosa falda ceñida a la cintura y pecho y mangas abullonadas. Es de piel blanca y sonrosada, con una vistosa melena rubia que le cae sobre su lado derecho. La cara es dulce, aunque apenada y triste. Tiene los ojos semicerrados, la nariz algo chata y la boca carnosa y perfilada, característica de las obras de Crayer. Los brazos son anchos, de tez lustrosa, las manos cuidadas, unidas en extrema devoción, con las uñas bien cortadas y perfiladas. La escena se completa con el joven y apuesto San Juan. Está de pie y sostiene el brazo izquierdo de Cristo en un intento de limpiar los restos de sangre y suciedad que le cubren. Con gran delicadeza, y en señal de respeto, se ayuda de un paño para sujetar la muñeca del brazo inerte de Cristo evitado el contacto directo con su piel. Con su mano derecha recoge el mismo lienzo preparado para purificar al Hijo de Dios. El discípulo amado viste una amplia túnica roja y cubre sus hombros y brazos con un ampuloso manto de profundos plegados (Fig. 7). Su rostro es algo aniñado, casi cubierto por una frondosa media melena de color castaño claro y de encrespada apariencia. Es de tez blanca y sonrosada con ojos saltones y algo enrojecidos por el llanto, ahora contenido. La nariz es prominente y de punta redondeada y la boca pequeña, carnosa y bien perfilada. Sus manos son finas y cuidadas, con dedos largos y elegantes, sin las huellas que dejan los rudos trabajos manuales. Los pies parecen grandes y algo huesudos, y los lleva descalzos, al igual que la Magdalena. 


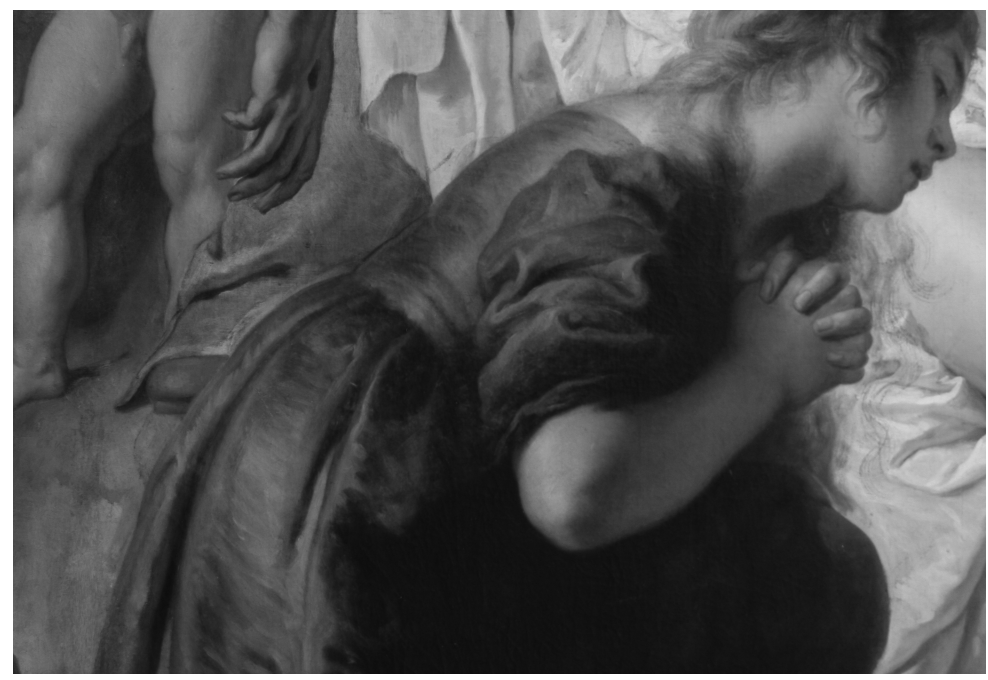

Fig. 6. Lamentación sobre Cristo muerto. Detalle de la Magdalena.

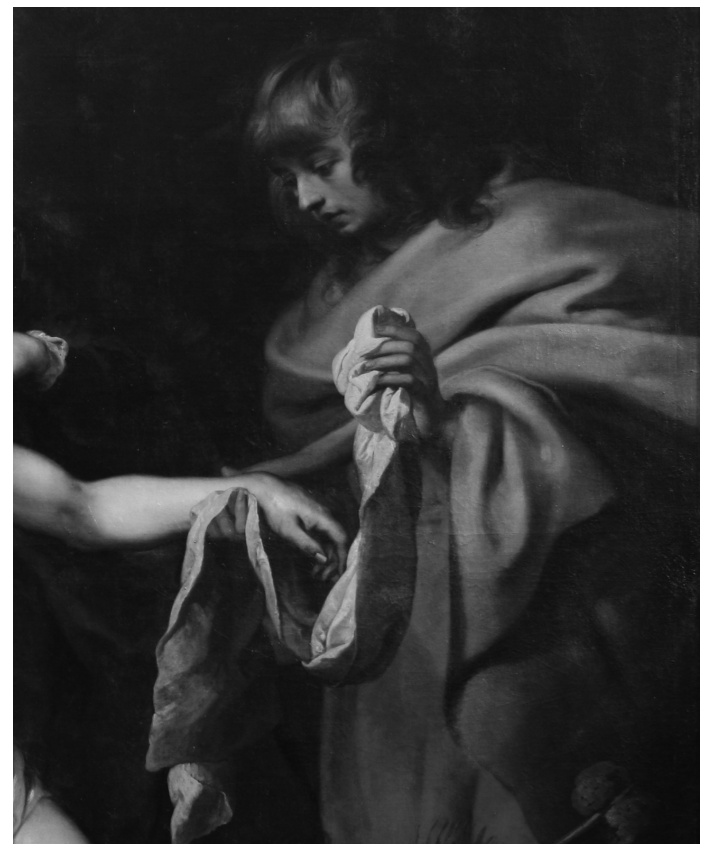

Fig. 7. Lamentación sobre Cristo muerto. San Juan.

Los cuatro protagonistas principales se acompañan de un reducido cortejo de ángeles que participan activamente en la escena. Todos ellos portan los Arma Christi, o instrumentos del martirio de Cristo. En primer plano a los pies de San Juan y 
de Cristo se sitúan dos rollizos angelotes en movida actitud. El primero tiene la pierna izquierda arrodillada y la derecha flexionada, y muestra con sus manos un haz de varas anudadas con las que Cristo fue azotado (Fig. 8). Está tan sólo cubierto por un manto de color verde turquesa que deja al desnudo casi todo su costado izquierdo. Es de cara alargada y rellenita, con buenos mofletes; de tez blanca y sonrosada, claramente norteña, y pelo rubio, algo rizado y desgreñado. Tiene el rostro apenado y desconsolado, con los ojos pequeños y semicerrados por el llanto que no cesa y que corre por sus mejillas. Es idéntico al que aparece en la obra titulada Cristo crucificado con San Francisco y la Magdalena del Museo de Bellas Artes de Saint Quentin ${ }^{51}$. Su compañero ocupa un plano más discreto, sentado y recostado sobre el montículo en el que Cristo y la Virgen están situados. Viste camisola blanca y manto marrón con el hombro izquierdo y la pierna al descubierto. Lleva en sus manos la vara con la esponja empapada en hiel que fue ofrecida a Cristo sediento. Es también de cara rolliza, con una magnífica melena de tono castaño y algo encrespada. Tiene los ojos grandes y turbados por el dolor y el llanto, ahora interrumpido. Es de nariz chata, boca pequeña y entreabierta, con labios carnosos y un simpático hoyuelo en el mentón que sobresale de su incipiente papada.

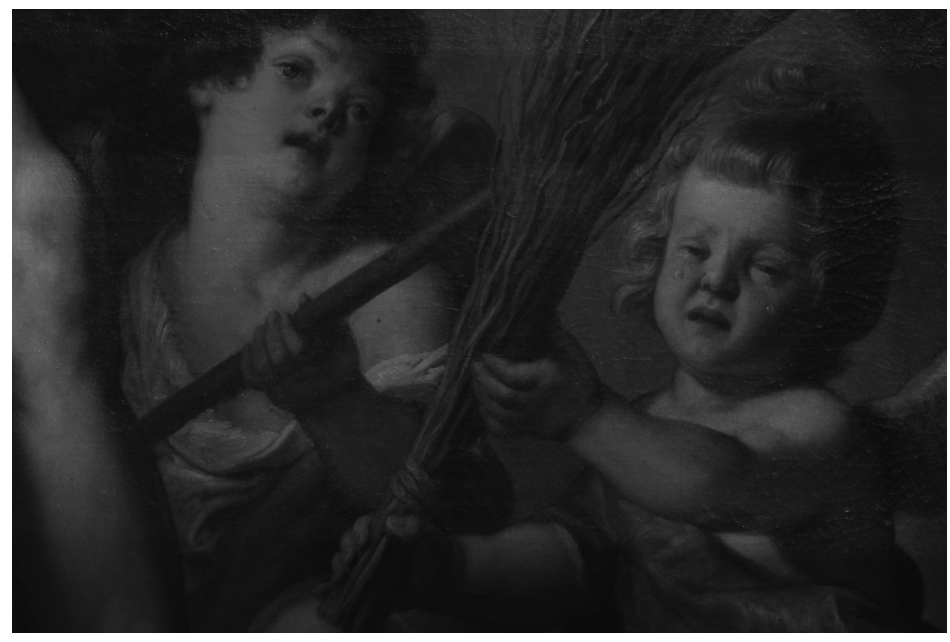

Fig. 8. Lamentación sobre Cristo muerto. Detalle de los Ángeles.

Al fondo y en un plano opuesto compensando la composición se sitúa el tercer ángel. Está de pie, en actitud movida y completamente desnudo, tan solo acompañado por un manto de tono dorado sujeto por su brazo izquierdo y por un cordón que cruza su pecho. Tiene un aspecto rollizo con una piel blanca y saludable, y un rostro movido y perturbado por el dolor (Fig. 9). En sus manos porta y

51 VLIEGHE, H., «Gaspar de Crayer. Addenda et corrigenda», Gentse Bijdragen tot de Kunstgeschiedenis, vol. XXV, Gante, 1979, p. 192, Fig. 34. 
muestra la corona de espinas dirigiendo su mirada al lugar del que procede este macabro atributo. Al igual que sus compañeros es de cara redonda y regordeta, con buenos mofletes e incipiente papada. Dispone de una agitada melena rubia y una expresión desencajada potenciada por unos ojos afligidos y una boca entreabierta que muestra un dolor difícilmente contenido. El cortejo de ángeles se completa con los situados en el ángulo superior izquierdo (Fig. 10). Se asoman entre nubes y parecen meros espectadores del dramático momento que se está viviendo en la escena. Portan la lanza y un pergamino con parte de la inscripción que se puso sobre la cruz en griego, latín y hebreo. Es evidente que no forman parte del conjunto y que fueron realizados por otra mano. No son tan frescos y llenos de vida como el resto y pecan de cierto estatismo y falta de naturalidad. Los rostros no logran la expresión de dolor contenido del resto de los personajes y más parecen enfadados o enfurruñados.

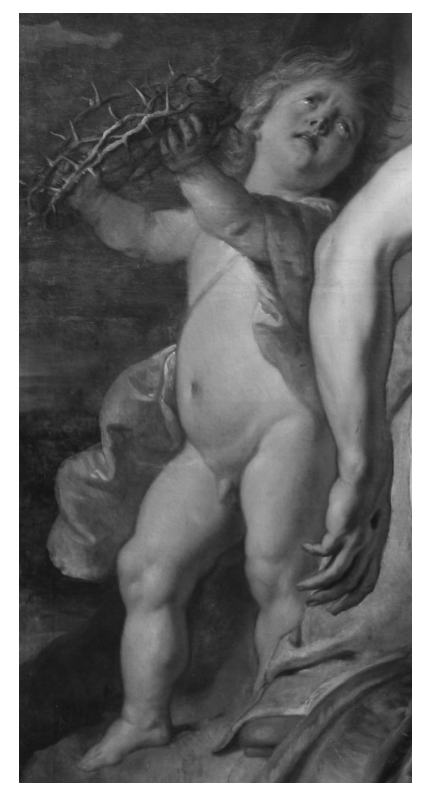

Fig. 9. Lamentación sobre Cristo muerto. Detalle Ángel con corona.

La obra está centrada en los personajes casi de manera individualizada, sin un efecto de conjunto excesivamente logrado. El fondo se emplea a la manera tenebrista, con una luz focal que proviene del ángulo superior izquierdo a modo de un rompimiento celestial. El efecto lumínico logrado es adecuado a las necesidades del tema, luctuoso y a la vez esperanzador. Aparte de los instrumentos empleados en el martirio de Cristo se incluye una hermosa jofaina en primer plano a los pies de Cristo. Es de cobre, con una amplia ala y contiene restos del agua ensangrentada de limpiar el cuerpo de Cristo. 


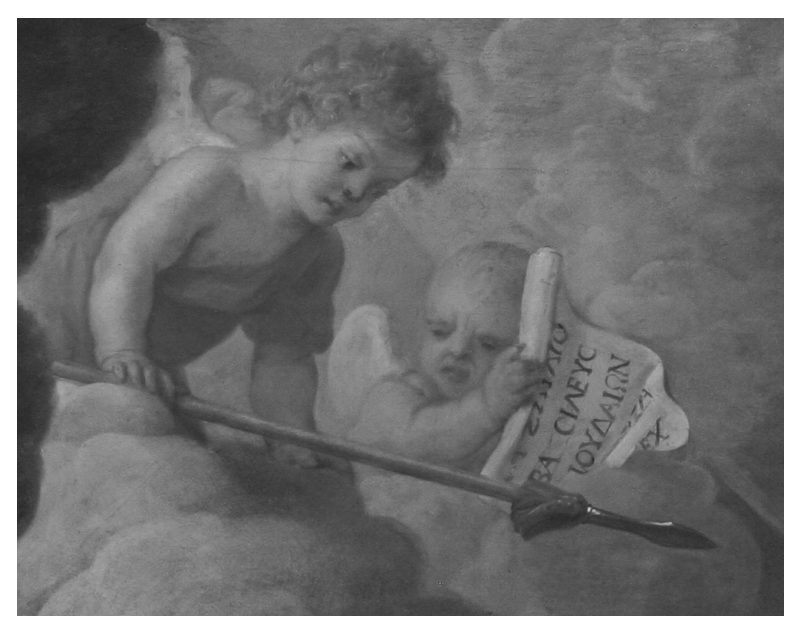

Fig. 10. Lamentación sobre Cristo muerto. Ángeles celestiales.

Como ya hemos comentado, el lienzo fue atribuido a Gaspar de Crayer en 1953 por Daphne M. Hoffman ${ }^{52}$. Esta atribución ha sido aceptada por la crítica y reconocida en la principal monografía dedicada a este pintor y publicada en 1972 por Hans Vlieghe ${ }^{53}$. Hoffman no se aventura a situar cronológicamente esta obra. Tan sólo Vlieghe considera que debe incluirse en la producción de Crayer comprendida entre 1638 y 1648 aproximadamente. La fecha que se viene utilizando sistemáticamente en los trabajos en los que se cita este lienzo es la de 1643, tomando como referencia la estancia de Francisco de Galarreta en Flandes, con motivo de la negociación secreta que Felipe IV le había encomendado ${ }^{54}$. No hay duda, de que se trata de una obra realizada en plena madurez artística, en la década de los años 40 o principios de los 50 , en la que ya ha superado la influencia de autores como Martín de Vos o Hendrick de Clerk y se abre a la expresión más barroca de Rubens y Van Dyck. Esta nueva savia en la obra de Crayer se advierte a partir de los años treinta y se hace manifiesta en la adopción de esquemas y modos empleados por estos afamados pintores. Fue a partir de los años cuarenta, tras la muerte de Rubens y Van Dyck, cuando Crayer empieza a ser plenamente reconocido y ocupa importantes puestos bajo la sombra de los Austrias. Hasta esas fechas había permanecido ensombrecido por la estela de estos dos grandes artistas vinculados a las más destacadas monarquías europeas. El tipo de pincelada blanda y colorista, acompañada de ojos vidriosos o en éxtasis que se emplea en este lienzo, es propio de las últimas décadas en la producción de Crayer. También el silueteado de las imágenes parece verse especialmente en sus obras de madurez.

\footnotetext{
52 HOFFMAN, D. M., Op. Cit., p. 99.

53 VLIEGHE, H., Op. Cit., p. 172.

${ }^{54}$ PORTILLA, M., Op. Cit., p. 46.
} 
En lo formal tiene muchas similitudes con la producción que Vlieghe sitúa entre 1638 y 1648. Los angelitos del cuadro de Vitoria son idénticos al Cristo crucificado entre San Francisco y María Magdalena del Museo del Louvre tomados de otra composición del Museo de Bellas Artes de Saint Quentin (1638-1645) ${ }^{55}$. Similares coincidencias encontramos en la Virgen y uno de los niños del San Agustín en éxtasis del Museo de Bellas Artes de Valenciennes o en el extraordinario estudio anatómico del Cristo del Descendimiento de la cruz del Rijksmuseum de Ámsterdam lo mismo que la devota Magdalena a los pies de Cristo ${ }^{56}$. Es una pintura elegante, siguiendo la estela dejada por Van Dyck. No obstante, la personalidad de Crayer está claramente presente en su expresión desapasionada, bien alejada del patetismo heroico de sus antecesores. Es un tema dramático que Crayer ha sabido resolver con un exquisito refinamiento sin tener que ahondar en exceso en el dolor y en el drama que supone la muerte del Hijo de Dios. Responde con esta obra a la devoción y propaganda contrarreformista que en estos momentos buscaba enaltecer tanto a la Iglesia como a la monarquía católica.

Gracias a la restauración llevada a cabo por el Servicio de Restauraciones de la Diputación Foral de Álava y a los análisis de laboratorio realizados, disponemos de una rica información técnica que de otra manera hubiera sido imposible conocer (Fig. 11). La preparación empleada para este lienzo es de color blanco y está compuesta principalmente por carbonato cálcico aglutinada en cola de origen animal. Se han encontrado además dos imprimaciones, una de color pardo y otra de color gris, las dos aglutinadas en aceite secante, seguramente aceite de lino ${ }^{57}$. Sobre este último estrato de imprimación se asientan, como es lógico, de una a tres capas de color superpuestas dependiendo de las necesidades de la obra, aunque la mayor parte de los colores están obtenidos con una capa única y gruesa. No obstante, se puede comprobar cómo en la túnica de San Juan se superponen tres estratos de color, dos de tono oscuro, y un tercero compuesto por un intenso bermellón con el que se modela y remata. Los azules que emplea la Virgen se consiguen mediante dos estratos de color, uno claro compuesto por índigo y albayalde para suavizar la intensidad y otro oscuro mediante índigo y azurita. El verde del vestido del ángel está compuesto por azurita, amarillo de plomo y estaño aclarado por albayalde y carbonato cálcico; se encuentra algo alterado por las reacciones químicas que se producen mezclado estos productos. El azul del fondo es un azul esmalte con algo de laca roja, carbonato cálcico y albayalde de esta manera se consiguen las distintas tonalidades e intensidades cerúleas ${ }^{58}$.

55 VLIEGHE, H., Op. Cit., p. 170. VLIEGHE, H., «Gaspar de Crayer. Addenda et corrigenda», Gentse Bijdragen tot de Kunstgeschiedenis, vol. XXV, Gante, 1979, p. 192, Fig. 34.

56 VLIEGHE, H., Op. Cit., Tomo II, Fig. 103 (A106), 119 (A122).

57 ARANSAY SAURA, C.; LÓPEZ VILLANUEVA, M., Op. Cit. pp. 342-343. Se especifican composiciones, proporciones y grosor.

58 ARANSAY SAURA, C.; LÓPEZ VILLANUEVA, M., Op. Cit. pp. 342-343. 


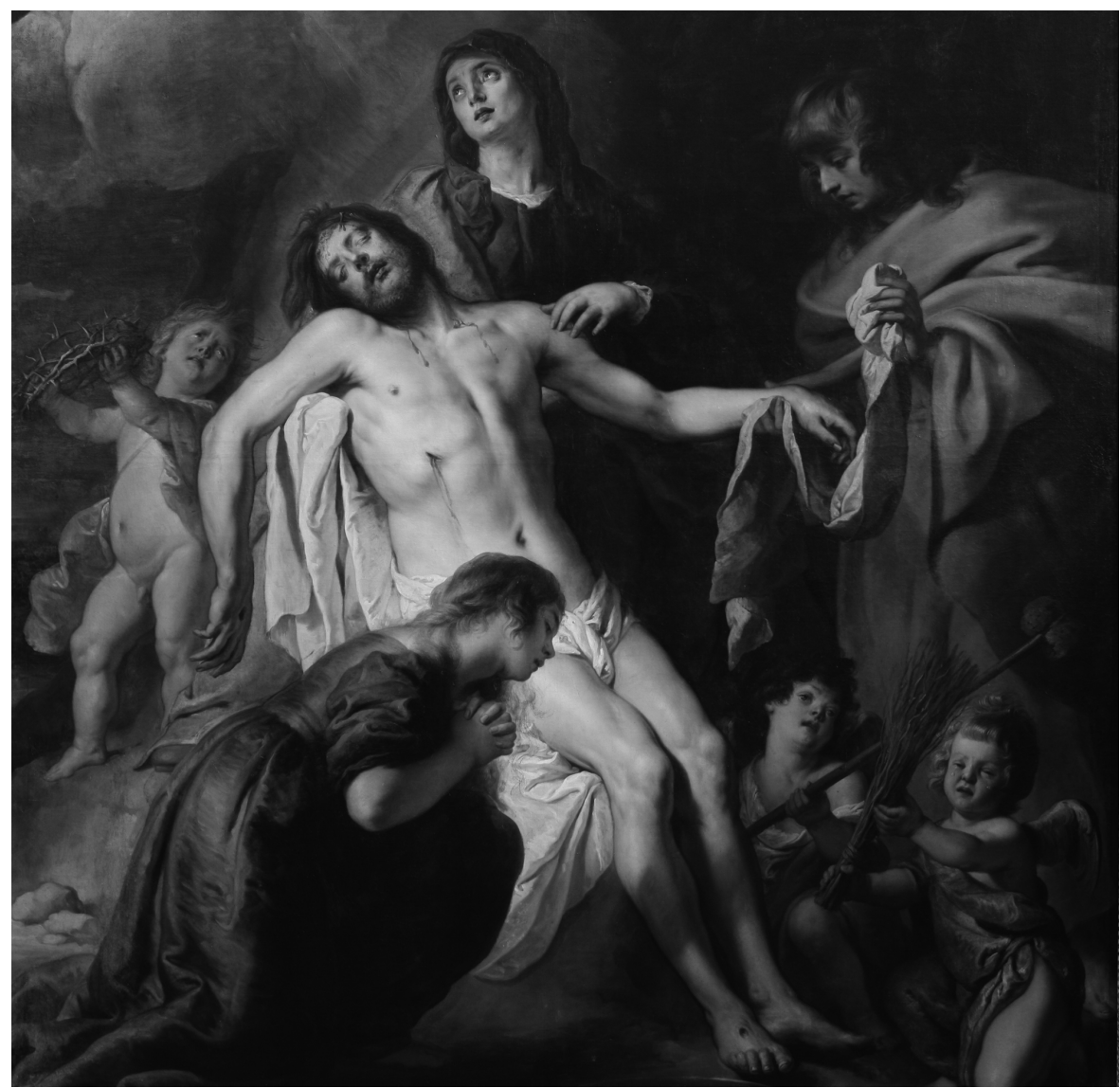

Fig. 11. Lamentación sobre Cristo muerto. Detalle.

La paleta empleada en el lienzo es amplia, como suele ser habitual entre los grandes pintores, pues los maestros más mediocres tienden a trabajar con un limitado abanico cromático. Los análisis químicos nos han permitido conocer los pigmentos y colores empleados, además de su cadencia de uso. De todo ello se extrae, que los más empleados fueron el carbonato cálcico, albayalde y negro hueso ${ }^{59}$. La paleta cromática está bien compensada y equilibrada, combinando los tonos calidos con los fríos, algo muy habitual en la producción de Crayer. La presencia de un intenso bermellón la encontramos en muchas de las obras de este pintor; se emplea en las ropas de personajes a destacar y en cortinajes que proporcionan un efecto teatral y escenográfico presente en la pintura de este siglo. Los azules también son constantes en la obra de este artista, normalmente destinados a la indumentaria de la Virgen, pues es el color que le corresponde, pero también

59 ARANSAY SAURA, C.; LÓPEZ VILLANUEVA, M., Op. Cit. pp. 342-343. 
utilizado en las ropas de otros personajes. El destinado a los fondos es de un tono menos intenso y con mayor nivel de gradaciones; en este caso queda reducido a un pequeño cuadrante tras el ángel que porta la corona de espinas. El tono verdoso de uno de los angelitos lo repite en otras composiciones, no ocurre lo mismo con el cálido granate aterciopelado de la Magdalena. Es evidente su destreza en el empleo del color, combinada con una delicada técnica de empaste de inconfundible transparencia. Tiende a utilizar colores fríos o neutros en los fondos y cálidos en las vestimentas, lo que crea un buen equilibrio cromático.

Para las encarnaciones hace uso de un gran número de matices dependiendo del personaje a representar. En el caso de Cristo, un hombre muerto y con las carnes tumefactas, utiliza una tonalidad mortecina conseguida mediante el uso de albayalde, carbonato cálcico y una laca roja muy fina y transparente ${ }^{60}$. En cambio, para los jóvenes ángeles, de pieles saludables y lozanas, emplea un intenso bermellón que enciende poderosamente la carnación dando un efecto rubicundo a las pieles. Este tipo de encarnaciones encendidas y rebosantes de vida, de tono casi rosáceo, son características de Gaspar de Crayer y empleadas dependiendo del personaje en casi todas sus obras. Es curioso que los dos cuerpos que aparecen casi completamente desnudos, Cristo y el ángel que porta la corona de espinas, están silueteados mediante una línea rojiza que delimita sus cuerpos. Este trazo busca demarcar el perfil y el contorno del cuerpo para separarlo del espacio. Es un importante instrumento gestual que contribuye a aumentar la expresividad y comunicación de las formas empleadas. Esta particularidad la hemos podido comprobar a simple vista en algunas obras tardías, de última etapa, como el San Antonio de Padua con el Niño Jesús que se conserva en el Museo Nacional del Prado fechado hacia 1655. El Niño desnudo está silueteado por una casi inapreciable línea que recorre algunas partes de su contorno. Aparte de esta línea de silueteado se aprecia un sombreado rojizo bajo el brazo y la axila de Cristo.

Nada tiene que ver este contorno rojizo con el dibujo subyacente que ha podido apreciarse, no sin dificultades, mediante un estudio de reflectografía infrarroja llevado a cabo por el Servicio de Restauración de la Diputación Foral ${ }^{61}$. Está realizado en la última capa de imprimación, y en muchos parajes apenas es apreciable debido a la intensidad y grosor de los estratos de color. En los lugares donde se advierte el dibujo se ha comprobado que está hecho a punta de pincel con un tono pardo y un trazo continuo. Este dibujo subyacente, oculto por la capa pictórica, nos puede aportar datos sobre las técnicas del diseño previo, el empleo de estarcidos, cuadrículas o la metodología de ejecución. Es evidente que los resultados en ocasiones son asombrosos, sobre todo en pinturas donde el dibujo es un protagonista esencial de la composición. No ocurre lo mismo en obras que, como ésta, apuestan por un trazo menos elaborado y potencian el uso del color con estratos gruesos y sucesivos. Son obras donde prima el color sobre el dibujo, en las que se

60 ARANSAY SAURA, C.; LÓPEZ VILLANUEVA, M., Op. Cit. pp. 342-343.

61 ARANSAY SAURA, C.; LÓPEZ VILLANUEVA, M., Op. Cit. pp. 342-343. 
impone la pincelada y se da más importancia al aspecto cromático. En la obra de Crayer la concepción lineal ayudada de una pincelada lisa es más apreciable en sus inicios, hasta los años 30 aproximadamente. A partir de esa década se apoyará más en el color y en una pincelada más blanda. En sus últimas obras, las realizadas a partir de los años 1650, empleará una factura más libre y contundente, pero evidentemente, muy alejada de la soltura y el nerviosismo inquieto de Van Dyck. La manera de Crayer en este lienzo se podría definir como meticulosa, de ejecución fina, con una pincelada potente, alegre, bien acabada y llena de matices, en la línea de las obras de plena madurez. El estilo general de esta obra coincide con la «Nobleza de la forma, elegancia y delicadeza del color» con la que ha sido calificada.

La composición empleada es ambiciosa, marcada por la potente y dramática diagonal de Cristo que se ve intensificada con un poderoso foco de luz, de raigambre tenebrista, que hace de su cuerpo inerte el objeto esencial de la composición (Fig. 11). El resto de los personajes forman parte del equilibrio general de la obra aportando mayor riqueza y dinamismo al conjunto. No obstante, frente a la riqueza y la armonía que se ha pretendido, se advierte una cierta incomunicación de los personajes. La única establecida se consigue mediante el tacto, con el compasivo vínculo creado entre la Virgen y San Juan, a quienes Cristo sirve de nexo de unión. El resto de personajes, forman evidentemente parte de la composición, pero sin establecer una relación real. Están individualizados, casi aislados, sin ninguna comunicación visual entre ellos, ni con el espectador, a quien no hacen partícipe directo del dramático momento. Se explotan los primeros planos remarcados por una luz casi tenebrista que incide sobre la blancura inmaculada del protagonista. El fondo queda casi por completo anulado a la manera tenebrista, en la línea de Gaspar de Crayer, a quien no le gustan las perspectivas elaboradas y tiende a emplear fondos anulados por una atmósfera tenue que en el mejor de los casos incluye elementos arquitectónicos de raíz rubeniana o ampulosos cortinajes, de carácter más escenográfico. Explota los primeros planos y se centra, como en este caso, en los personajes a quienes representa de forma monumental e individualizada. En esta obra, además, casi todos se caracterizan por tener unas excesivas torsiones de cuello.

El lienzo se centra en la Lamentación sobre Cristo muerto, un tema ligado a la Piedad y situado entre el Descendimiento y el Santo Entierro. Es un episodio apócrifo aunque cercano a un texto del Evangelio según San Juan en el que se narra el momento anterior al entierro de Cristo ${ }^{62}$. La Piedad es un tema más intimista

62 Juan 19:38-42 «Después de esto, José de Arimatea, que era discípulo de Jesús, aunque en secreto por miedo a los judíos, pidió a Pilato autorización para retirar el cuerpo de Jesús. Pilato se lo concedió. Fueron, pues, y retiraron su cuerpo. Fue también Nicodemo - aquel que anteriormente había ido a verle de noche - con una mezcla de mirra y áloe de unas cien libras. Tomaron el cuerpo de Jesús y lo envolvieron en vendas con los aromas, conforme a la costumbre judía de sepultar. En el lugar donde había sido crucificado había un huerto, y en el huerto un sepulcro nuevo, en el que nadie todavía había sido depositado. Allí, pues, porque era el día de la Preparación de los judíos y el sepulcro estaba cerca, pusieron a Jesús». 
resuelto con la presencia de Cristo en el regazo de la Virgen, mientras que la Lamentación se muestra más narrativa y con un mayor número de personajes. En realidad la iconografía de la Piedad deriva del threnos bizantino que no es más que la lamentación de la Virgen sobre el cuerpo muerto de Cristo. El tema hunde sus raíces por tanto en el arte bizantino, donde aparece por primera vez, y se impregna de la literatura mística medieval. En este lienzo se ha elegido el momento en el que la Virgen ubica el cuerpo de su hijo entre sus rodillas, rodeado de personas que se lamentan por su muerte. Sigue por tanto la línea más tradicional y pasional del tema, pero añade un detalle interesante, el instante en el que el cuerpo de Cristo fue lavado para posteriormente ungirlo con mirra y áloe y amortajarlo con el sudario, según narra el Evangelio de San Juan. Esta costumbre se practicaba en los ritos funerarios judíos, que mezclaban mirra y áloe en los ungüentos para preservar y perfumar los cuerpos antes de su amortajamiento. Este momento purificador se advierte con claridad en la disposición de San Juan con el paño en la mano y en la presencia de la jofaina, en primer plano, con restos de sangre.

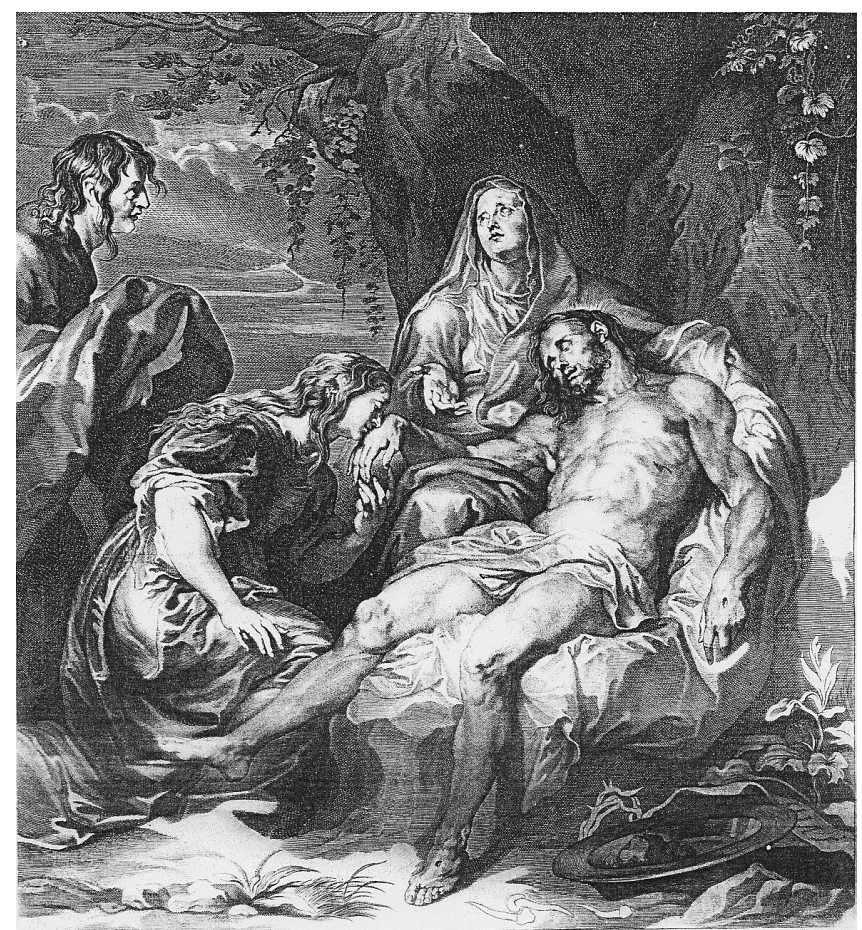

Fig. 12. Paulus Pontius según composición de Anton van Dyck. Llanto sobre Cristo muerto.

La fuente de inspiración para la creación de este cuadro hay que buscarla entre los pintores flamencos que le precedieron. Una composición con grandes similitudes la encontramos en la Lamentación realizada por el pintor flamenco 
Hendrik de Clerck. Esta obra se encuentra en la iglesia de Santa Prassede en Todi (Italia) y presenta el tema con interesantes puntos de conexión con la obra de Crayer. Su disposición es mucho más apretada, los personajes tropiezan unos con otros, pero las coincidencias vale la pena destacarlas. La Virgen sujeta el cuerpo inerte de Cristo con su mano derecha bajo la axila y sobre el pecho; de la misma forma se representa en la obra de Crayer, salvo que su mano está oculta, respetuosamente, bajo el sudario. San Juan sostiene el brazo de Cristo y la Magdalena está arrodillada en fervorosa oración de manera similar al lienzo de Crayer aunque en el lado contrario. La diferencia más acusada está en la presencia de José de Arimatea junto al brazo derecho de Cristo. No hay duda de que la producción de Rubens o Van Dyck fueron dos referencias determinantes en la obra de Gaspar de Crayer. El tema de la Lamentación fue pintado y reproducido en distintas ocasiones por estos famosos pintores. Pero es indiscutible la deuda formal e iconográfica que tiene la obra de Crayer con la de Van Dyck. Este extraordinario pintor realizó varias versiones del tema, todas ellas bien conocidas y reproducidas a través de grabados. Una de las más importantes fue el Llanto sobre Cristo muerto realizado para un beaterio de beguinas de Amberes, donde Van Dyck quiso ser enterrado. De esta obra realizó una réplica reducida con mínimas variantes, que Paulus Pontius grabó, propagando esta composición entre otros artistas (Fig. 12). Su éxito hizo que posteriormente fuera grabada por François Ragot, Hendrick Snyers y Johann Nepomuk ${ }^{63}$. Con el mismo tema Anton van Dyck pinto otro lienzo encargado por el diplomático Cesare Allesandro Scaglia en 1634. Esta famosa obra fue grabada fielmente por Lucas Vorsterman probablemente hacia 1634 y 1638 y comercializada por el propio Van Dyck. Hacia 1636 Van Dyck volvió a repetir el tema grabado en esta ocasión por Schelte à Bolswert ${ }^{64}$. Aunque la pintura de Crayer no es en ningún caso una réplica de estas composiciones, sí que es evidente su filiación formal. El rostro de la Virgen es un calco de las reproducidas por Van Dyck; esto mismo podría hacerse extensible al resto de los personajes que Crayer emplea en este cuadro.

Un examen visual exhaustivo, ayudado por análisis químicos y estudios radiográficos nos ha permitido conocer que el tamaño original del cuadro fue modificado posteriormente. La tela central está ampliada por dos bandas de lienzo cosidas en su parte superior e inferior. El soporte textil es también diferente, pues en el primero se emplea lino y en los añadidos cáñamo, cosidos a punto de Bolonia. A esto hay que sumar que la preparación encontrada en estas dos bandas también es distinta a la del paño central. Está compuesta de dos capas, una blanquecina hecha de carbonato cálcico, tierras y albayalde, y la otra gris, con albayalde, carbonato cálcico y carbón vegetal. También los colores y pigmentos empleados en las dos bandas añadidas tienen una composición diferente a los del

63 DEPAUW, C., LUISTEN, G., Anton van Dyck y el arte del Grabado, Madrid, 2003, pp. 258-262.

${ }^{64}$ DEPAUW, C., LUISTEN, G., Op. Cit. pp. 263-266. DEPAUW, S. (Ed.), The New Hollstein, Dutch \& flemish etchings, engravings and woodcuts 1450-1700. Anthony van Dyck, part IV, Rotterdam, 2002, pp. 119-155. 
paño central ${ }^{65}$. A todos estos interesantes datos extraídos por los análisis de laboratorio y estudios complementarios hechos por el Servicio de Restauraciones de la D.F.A. hay que añadir que con un simple examen visual se puede advertir con absoluta claridad la diferencia estilística existente entre los dos ángeles de la banda superior y el resto de los personajes del lienzo. Sus carencias formales son más evidentes al compararlas con el conjunto atribuido a Crayer, pues queda de manifiesto la mano de otro pintor de menor destreza. No son estos los únicos cambios que se advierten en el lienzo, pues gracias a un meticuloso estudio radiográfico llevado a cabo por las restauradoras se ha podido descubrir que la jofaina del primer plano estuvo en su origen situada un poco más arriba, junto a los pies de Cristo66.

Estas modificaciones de aspectos formales y estéticos del cuadro debieron producirse entre el momento de su ejecución y 1785, fecha en la que el lienzo fue descrito incluyendo estos dos ángeles del remate superior ${ }^{67}$. La falta de documentación al respecto no nos permite conocer con certeza los motivos por los que este lienzo fue transformado. Sirva como hipótesis la posibilidad de que esta obra fuera concebida con menores dimensiones, destinada a formar parte del ajuar doméstico de alguna casa de los Galarreta. Cuando hacia 1663, momento en el que se terminaba de construir la capilla del Cristo, fue colocada en la aneja de San Prudencio por Martín de Galarreta, se debió decidir modificar la obra para poder adaptarla a un espacio mucho mayor.

El redescubrimiento de esta obra por destacados artistas de la corte y su traslado a la sacristía en 1785 dio como resultado la difusión de esta magnífica pintura. Es a partir de estos momentos cuando comienza a poner en valor, como ya hemos comprobado, entre viajeros, ilustrados e intelectuales que visitan la ciudad. También los artistas locales demuestran su interés por ella; no hay más que comprobar cómo el pintor José López de Torre en algunas composiciones parece inspirarse en esta obra. Lo mismo que su compañero y amigo, el escultor Mauricio de Valdivielso, que llevó esta pintura a tres dimensiones en la talla de la Piedad realizada para la iglesia de Ibarra. La obra debió ser, junto con la Inmaculada de Carreño o los Ribera, modelo para profesores y alumnos de la Escuela de Artes y Oficios de Vitoria. No es extraño por tanto encontrar copias de estos cuadros realizadas durante el siglo XIX. Buen ejemplo tenemos en el lienzo de la Lamentación que Claudia Aranguren, viuda del polifacético artista Carlos Imbert, regaló a la capilla de la Blanca según consta en el acta de la junta del 25 de marzo de 1870. Junto a esta obra incluía una copia del Santo Cristo de Ribera68.

65 ARANSAY SAURA, C.; LÓPEZ VILLANUEVA, M., Op. Cit. pp. 342-343.

66 ARANSAY SAURA, C.; LÓPEZ VILLANUEVA, M., Op. Cit. p. 344.

67 Documento cedido por la familia Eseverri a la Fundación Catedral Santa María. Junta de patronato 12 de mayo de 1785. ARANSAY SAURA, C.; LÓPEZ VILLANUEVA, M., Op. Cit. p. 341.

68 MARTín, P., Nuestra Señora la Blanca. Historias de su cofradía, 2003, pp. 118-119. 
Esta exitosa composición, al servicio de la contrarreforma y de la Iglesia, debió encajar muy bien entre los fieles devotos de la Europa católica. Fueron muchos los pintores que aprovecharon las posibilidades de este tema, siguiendo las más afamadas y difundidas composiciones de Rubens o Van Dyck. El propio Crayer realizó distintas versiones del mismo tema, llenas de la discreta elegancia que le caracterizaba. Su clientela, vinculada a la dinastía de los Austrias, supo apreciar estas obras recompensándole con buenos encargos con los que difundió los ideales políticos y religiosos de la monarquía española y de la Iglesia. La Lamentación sobre Cristo muerto que aquí hemos estudiado es un claro ejemplo de su éxito como pintor de corte al servicio de la monarquía y de sus más destacados políticos y cortesanos. Aunque todavía son muchas las incógnitas que rodean a este magnífico lienzo, con este artículo hemos querido reordenar todo lo escrito a modo de estado de la cuestión y aportar nuevos datos que sirvan para esclarecer algunos de los enigmas que sobre esta obra se ciernen. 
Cap07 14/11/2011 13:21 Página 180

$\otimes$ 